
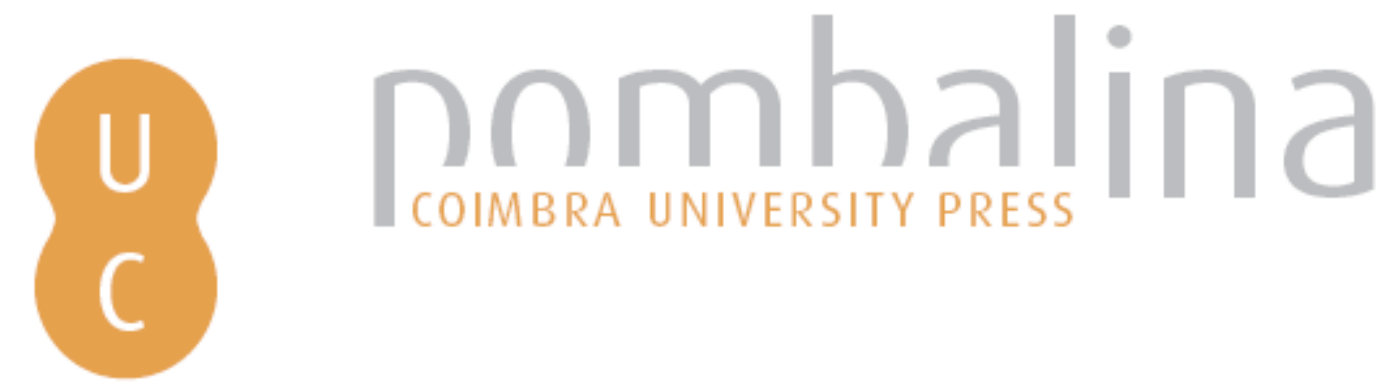

\title{
La transformación de una profesión: los farmacêuticos me xicanos de finales del siglo XIX
}

\author{
Autor(es): $\quad$ Solis, Sandra Martinez; Pastrana, Patricia Aceves; Cosme, Alba Morales \\ Publicado por: Imprensa da Universidade de Coimbra \\ URL \\ persistente: URI:http://hdl.handle.net/10316.2/32404 \\ DOI: $\quad$ DOI:http://dx.doi.org/10.14195/978-989-26-0469-5_19 \\ Accessed : $\quad$ 26-Apr-2023 13:51:02
}

A navegação consulta e descarregamento dos títulos inseridos nas Bibliotecas Digitais UC Digitalis, UC Pombalina e UC Impactum, pressupõem a aceitação plena e sem reservas dos Termos e Condições de Uso destas Bibliotecas Digitais, disponíveis em https://digitalis.uc.pt/pt-pt/termos.

Conforme exposto nos referidos Termos e Condições de Uso, o descarregamento de títulos de acesso restrito requer uma licença válida de autorização devendo o utilizador aceder ao(s) documento(s) a partir de um endereço de IP da instituição detentora da supramencionada licença.

Ao utilizador é apenas permitido o descarregamento para uso pessoal, pelo que o emprego do(s) título(s) descarregado(s) para outro fim, designadamente comercial, carece de autorização do respetivo autor ou editor da obra.

Na medida em que todas as obras da UC Digitalis se encontram protegidas pelo Código do Direito de Autor e Direitos Conexos e demais legislação aplicável, toda a cópia, parcial ou total, deste documento, nos casos em que é legalmente admitida, deverá conter ou fazer-se acompanhar por este aviso.

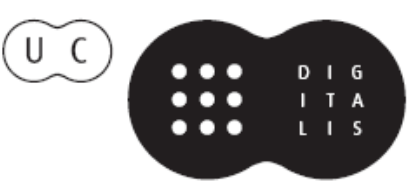


Ana Leunar Pereira João Rui Pita

[ Coordenaçä̃ ]
Rotas da Natureza

Cientistas

Viagens

Expedifgũes

Instituip̧ües

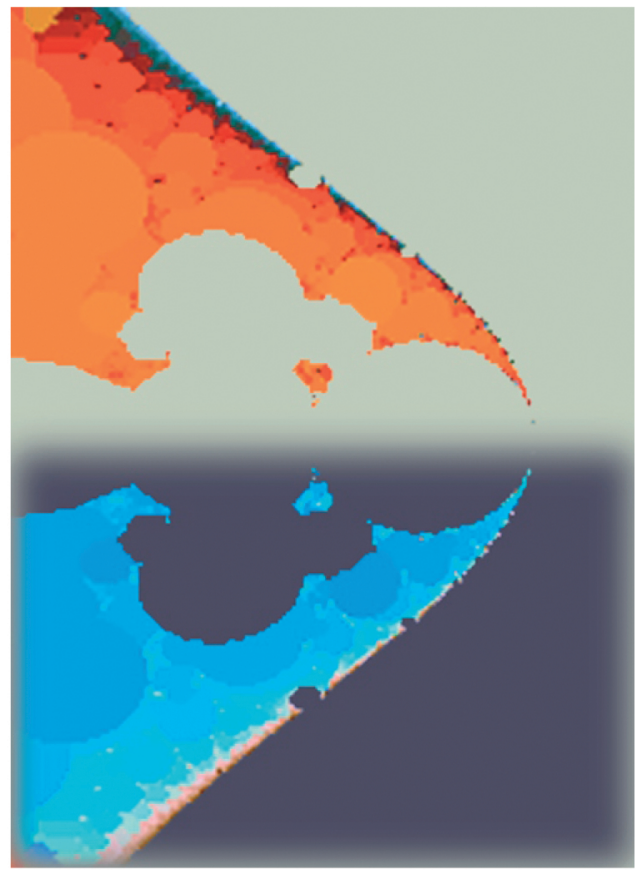




\section{Coordenaçáo Científica da Colecção Ciências e Culturas}

João Rui Pita e Ana Leonor Pereira

Os originais enviados são sujeitos a apreciação científica por referees

\section{Coordenação Editorial}

Maria João Padez Ferreira de Castro

\section{Edição}

Imprensa da Universidade de Coimbra

Email:impresauc@ci.uc.pt

URL: http://www.imp.uc.pt • Normas de publicação de colecçôes

\section{Design}

António Barros

Pré-Impressáo

António Resende

Imprensa da Universidade de Coimbra

\section{Capa}

António Barros, com imagem de E. M. de Melo e Castro, 2003 [Fractal original gerado no Fractint com tratamento no Photoshop 7.0]; Cortesia: António Barros

Impressão e Acabamento

SerSilito • Maia

\section{ISBN}

978-989-8074-12-6

\section{Depósito Legal}

Obra publicada com a colaboraçáo de:
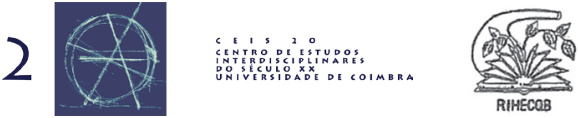

Obra publicada com o apoio de:

FCT Fundação para a Ciência e a Tecnologia

MINISTÉRIO DA CIÊNCIA, TECNOLOGIA E ENSINO SUPERTOR Portug

Programa Operacional Ciência, Tecnologia, Inovação do Quadro Comunitário de Apoio III
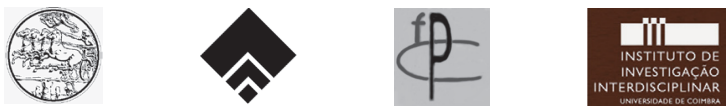

\section{Baxter}

(c) 2006, Imprensa da Universidade de Coimbra 
João Rui Pita

Ana Leonar Pereira

(Courdenação)

Rotas da Natureza

Cientistas

Viagens

Expediçũes

Instituiç̃̃es

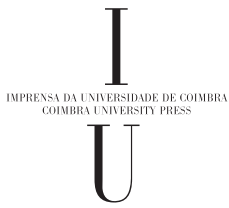

- colmbra 2006 
(Página deixada propositadamente em branco) 


\author{
Sandra Martinez Solis*; Patricia Aceves Pastrana** e Alba Morales Cosme** \\ * Universidad Nacional Autónoma de México \\ ** Universidad Autónoma Metropolitana - Xochimilco, México
}

\title{
LA TRANSFORMACIÓN DE UNA PROFESIÓN LOS FARMACÊUTICOS MEXICANOS DE FINALES DEL SIGLO XIX
}

En el último tercio del siglo XIX, los profesionales de la farmacia buscaron foros para discutir las insuficiencias de su formación que les impedían desarrollarse profesionalmente. A la vez, también destacaron la utilidad de su disciplina en el área de las ciencias químicas y biológicas, cuyas aplicaciones se extendían o podían hacerlo a los ámbitos educativo, industrial y comercial.

A partir de 1893, los farmacéuticos, iniciaron una revisión de los contenidos curriculares y del ejercicio práctico de su profesión, hasta entonces ligada a la Escuela de Medicina. El bajo nivel académico de los planes de estudio, la falta de una legislación clara y concisa, la carencia de espacios para desarrollarse y el encontrarse bajo la tutela de los médicos, eran factores que frenaban el desarrollo de su actividad, y su acceso a los nuevos campos emergentes relacionados con la química y la bacteriología; limitando sus posibilidades laborales al simple despacho de recetas en una botica.

Para hacer frente a esta situación, los farmacéuticos pugnaron constantemente por separarse de la Escuela de Medicina. Sin embargo, la buscada separación comenzaría a tomar forma hasta 1913, año en que surgieron los primeros proyectos formales para separar la carrera de Farmacia de la Escuela de Medicina y fundar una Escuela especial de Farmacia.

En este trabajo se analizan los primeros proyectos para separar la carrera de Farmacia de la Escuela de Medicina, así como las ideas que impulsaron a los farmacéuticos a diversificar su quehacer hacia una nueva faceta en la que también se desarrollarían como químicos ${ }^{1}$.

\section{La carrera de farmacia se transforma}

La enseñanza institucional de la farmacia se inició en 1833 con la apertura de la primera cátedra de farmacia en el recién creado Establecimiento de Ciencias Médicas ${ }^{2}$.

\footnotetext{
${ }^{1}$ Este trabajo forma parte de la tesis de Licenciatura en Historia de Sandra Martínez Solis, asesorada por Patricia Aceves Pastrana. Ver: Desarrollo y transformación de la Farmacia en México (1890-1920): las primeras mujeres farmacéuticas, Facultad de Filosofía y Letras, Universidad Nacional Autónoma de México, 2003,182 pp.

${ }^{2}$ Pasado algún tiempo el Establecimiento cambió su nombre a Escuela Nacional de Medicina.
} 
Esta iniciativa fue el resultado de las reformas a la educación decretadas por el vicepresidente de México Valentín Gómez Farías, las cuales también incluyeron el cierre de la Real y Pontificia Universidad ${ }^{3}$.

Durante el siglo XIX, la carrera de farmacia estuvo conformada únicamente por tres materias: farmacia teórico-práctica, historia natural de las drogas simples, y el primer y segundo cursos de análisis químico. Para 1893, los farmacéuticos interesados en la modernización de su profesión, lograron la creación de una clase de farmacia práctica impartida en el laboratorio del Almacén Central de la Beneficencia Pública subordinado al Consejo Superior de Salubridad; sin embargo, sus esfuerzos resultaron insuficientes y para 1895 , las clases en este laboratorio habían sido abandonadas.

Los farmacéuticos continuaron la lucha por modernizar sus planes de estudio, y a nombre de la Sociedad Farmacéutica Mexicana, le solicitaron al Secretario de Instrucción Pública la ampliación de su plan de estudios. Con este propósito pidieron se incluyeran un curso de bacteriología durante el primer año de la carrera, una cátedra de química médica hasta entonces restringida a los médicos, y el establecimiento de una clase práctica oficial, una especie de clínica, que se cursaría en dos años.

En el nuevo Plan de Enseñanza de la Medicina dado a conocer en 1902, le fue negado a la carrera de Farmacia el aumento de los cursos propuestos por la Sociedad Farmacéutica, únicamente se aceptó la inclusión del estudio de la bacteriología, aunque comprendida en el segundo curso de análisis químico ${ }^{4}$. Al ver frustradas sus aspiraciones profesionales, los farmacéuticos se dieron a la tarea de materializar un proyecto que los separara de la Escuela de Medicina, con el fin de tener mayores oportunidades para desarrollarse, conseguir mejores fuentes de empleo, y emanciparse de los médicos. Con esta mira en mente continuaron en su empeño de ampliar sus planes de estudio buscando diversificar su campo de trabajo.

En 1908, los farmacéuticos estrenaron un plan de estudios que además de incluir las materias citadas anteriormente, añadía las cátedras de legislación farmacéutica y bacteriología. A partir de ese año, las actualizaciones en los planes de estudio se hicieron más frecuentes, casi en períodos de dos años en promedio. Para 1916 contaban ya con un plan que privilegiaba los conocimientos de química sobre los referidos a la preparación de medicamentos. Este plan contaba con las materias de farmacia química mineral, historia natural de las drogas simples y nociones de micrografía y microfotografía, análisis químico general cuantitativo y cualitativo, química farmacéutica orgánica, química legal y legislación farmacéutica, bacteriología teórico-práctica, farmacia galénica con nociones de economía y contabilidad farmacéuticas; así como análisis de alimentos y bebidas e investigaciones bioquímicas.

\footnotetext{
${ }^{3}$ Aceves, Patricia. "Hacia una farmacia nacional: la primera farmacopea del México Independiente», en Farmacia, Historia Natural y Quimica Intercontinentales, Estudios de Historia Social de las Ciencias Quimicas y Biológicas, N. 3, México, (Aceves P. ed.) UAM-Xochimilco, 1995, p. 161-178.

${ }^{4}$ Hinke, Nina. «Entre arte y ciencia. La farmacia en México a finales del siglo XIX», en Relaciones Estidos de Historia y Sociedad. México, El Colegio de México, otoño 2001, vol. 22, pp. 61-62
} 


\section{Los planes de separación}

Las aspiraciones de los farmacéuticos por conseguir una escuela propia se habían intensificado con el trascurso del tiempo, ya desde 1894, durante el Segundo Congreso Médico Mexicano habían presentado formalmente la propuesta de crear una escuela de farmacia independiente de la de medicina, argumentando que la separación ayudaría a optimizar su ejercicio profesional ${ }^{5}$. Sin embargo, esta petición comenzó a tomar forma hasta diciembre de 1913, cuando el director de la Escuela de Medicina ordenó la creación de una comisión integrada por Ricardo Caturegli, Víctor Lucio y Juan B. Calderón ${ }^{6}$, encargados de analizar la viabilidad del proyecto de separación ${ }^{7}$.

Bajo el argumento de que su proyecto buscaba activar el proceso de industrialización en México, los demandantes incluían como una de sus propuestas la creación de la Escuela de Química y Farmacia. Los beneficios que acarrearía a la nación una escuela de este tipo eran numerosos para los diversos sectores relacionados con la química. Tal es el caso de la agricultura; la minería, particularmente en el ramo de la extracción del petróleo; la industria, donde se buscaba que los químicos egresados de la Escuela reemplazaran a los extranjeros y le dieran un fuerte impulso; y la conservación de la salud, sobre todo en las ramas de higiene pública, análisis toxicológicos y de autenticidad de sustancias para evitar las falsificaciones. Además la Escuela tendría como meta, poner a México a la altura de los países más desarrollados en el aspecto industrial ${ }^{8}$.

Con el propósito de darle seguimiento a la propuesta en 1914 se formó una comisión y para profundizar en los planteamientos de la misma, se integró otra más en 1916, compuesta por Ricardo Caturegli, Adolfo P. Castañares y Miguel Cordero9?. Entre los

${ }_{5}$ Memorias del Segundo Congreso Médico Mexicano. Celebrado en San Luis Potosí del 5 al 8 de noviembre de 1894. 2v. México [S.P.I.] 1895. p. 389.

${ }^{6}$ Ricardo Caturegli, nació en Hermosillo, Sonora y obtuvo el título de farmacéutico por la Escuela Nacional de Medicina en 1901, institución en la que impartió la cátedra de análisis de alimentos y bebidas e investigaciones bioquímicas. Al pasar la carrera de farmacia a la Facultad de Química, ingresó como profesor y en 1924 fue nombrado director de la escuela. Por su parte, Víctor Lucio fue discípulo y ayudante de Leopoldo Río de la Loza, obtuvo el título de médico y tuvo a su cargo la cátedra de análisis químico general cualitativo y cuantitativo, impartida en la Escuela de Medicina para los estudiantes de farmacia. Juan B. Calderón impartía la cátedra de legislación farmacéutica en la misma institución.

${ }^{7}$ Los farmacéuticos integrantes de la comisión intentaron que se les otorgaran las instalaciones del Instituto Médico Nacional; sin embargo, en los proyectos posteriores no se volvió a tratar el asunto. Cabe aclarar que posiblemente esta comisión fue nombrada como consecuencia de la propuesta de Juan Salvador Agraz para fundar una Escuela de Química que data de enero del mismo año, aunque en un documento posterior asegura nunca haber tenido la intención de incluir a la farmacia dentro de las carreras que se impartirían en la Escuela. Semblanza del señor ingeniero don Juan Salvador Agraz. México, edición particular, 1981. 116, pp. Ils.

${ }^{8}$ Ahfm-unam.Escuela de Medicina y Alumnos, leg. 166, exp. 3. Proyecto para la fundación de la Escuela Especial de Quimica y Farmacia. México, 9 de diciembre de 1913, f.11.

${ }^{9}$ Adolfo P. Castañares nació en 1880 en Villahermosa, Tabasco. Cursó los estudios de farmacéutico en la Escuela Nacional de Medicina. En 1904, obtuvo una beca de la Secretaría de Instrucción Pública y Bellas Artes para perfeccionar sus estudios en Berlín, Alemania. Durante su estancia en esa ciudad, el gobierno de México lo comisionó para representar al país en el Congreso de Química Aplicada celebrado en Roma, en el que tuvo una destacada participación; poco antes de su regreso a la nación, la Secretaría de Instrucción Pública y Bellas Artes le encargó realizar algunas visitas de inspección y estudio a los labora- 
aspectos más importantes del plan de 1916, estaban los proyectos para crear una farmacia especialmente dedicada a la práctica de los alumnos y la producción de medicamentos a gran escala; incluso se proponía la fundación de laboratorios especiales para el desarrollo de las ramas químicas susceptibles de ser explotadas industrialmente ${ }^{10}$. Dichos laboratorios aliviarían la dependencia del país con los centros productores extranjeros y estimularían la competencia en calidad y cantidad con miras a la exportación ${ }^{11}$. Además, tendrían la función social de ofrecer medicamentos de buena calidad a bajos precios para beneficiar a los sectores más necesitados de la población. Por esta razón y para no constituir una competencia desigual, que entorpeciera el crecimiento de la industria privada, se reservarían sus productos únicamente a los establecimientos ligados a la Beneficencia Pública y al Ejército ${ }^{12}$.

La oportunidad esperada por los farmacéuticos llegó hasta enero de 1919, cuando Adolfo P. Castañares en acuerdo con el Rector de la Universidad, José Natividad Macías ${ }^{13}$, presentó el plan que fusionaría la carrera de Farmacia con la Facultad de Ciencias Químicas ${ }^{14}$. En su proyecto, Castañares además de exponer los beneficios económicos de la unificación, argumentaba que la farmacia ya no se encontraba en un estado de subordinación a la medicina, y para evitar el atraso provocado por la tutela de los médicos sobre ella debía orientarse hacia campos relacionados con la química moderna ${ }^{15}$. En opinión de Castañares, la farmacia contaba con la química como su base más sólida, por lo que el farmacéutico tenía la «imperiosa necesidad de adquirir muy sólidos, amplios y profundos conocimientos en química general y análisis químico, tal y como debe poseerlos el químico industrial» ${ }^{16}$.

En esta línea de acción, los farmacéuticos diversificaron cada vez más sus estudios, introduciendo conocimientos modernos sobre la producción industrial de fármacos

torios químicos existentes en las universidades de Viena, París, Londres y Roma. Una vez en México, se desempeñó como profesor de química orgánica aplicada a la farmacia en la Escuela Nacional de Medicina; así mismo, fue el primer químico mexicano en preparar aire líquido en el país. En 1916 representó a la nación en el Congreso Internacional de Química Aplicada, celebrado en Washington, donde nuevamente destacó su participación. Murió el 15 de agosto de 1919, cuando contaba con 39 años a causa de una enfermedad crónica. Horacio García Fernández. Historia de una Facultad, Química, México, Facultad de Química. UNAM, 1985. pp. 27-28.

${ }^{10}$ Ahfm-unam. Escuela de Medicina y Alumnos, leg. 228, exp. 7. Proyecto de Plan de Estudios de la Facultad Independiente de Farmacia. México, 15 de agosto de 1916, f. 3.

${ }^{11}$ Ibidem

${ }^{12}$ La oficina farmacéutica, cumpliría con una labor muy parecida a la planeada para el Laboratorio Central en la época de su creación.

${ }^{13}$ Ahfm-unam. Escuela de Medicina y Alumnos, leg. 228, exp. 7. Proyecto de Plan de Estudios de la Facultad Independiente de Farmacia. México, 15 de agosto de 1916, f. 3.

${ }^{14} \mathrm{La}$ antecesora de esta última fue la Escuela Nacional de Industrias Químicas creada en 1916 a iniciativa del ingeniero químico Juan Salvador Agraz.

${ }^{15}$ Bezanilla Testa, Triunfo. «Un hecho histórico sobre la Facultad de Farmacia. Evolución de la Escuela de Ciencias Químicas», en Química y farmacia. T. 13, núm. 25. Agosto de 1949, págs. 23-24.

${ }^{16}$ CESU. Fondo: Ciencias Quimicas. Sección: Dirección. Serie: Decretos, acuerdos, comunicados, etc., caja 1, exp. 3 [Comunicado de Adolfo P. Castañares a Juan N. Macías, respondiendo a las objeciones de Juan Salvador Agraz, sobre la conveniencia de que la carrera de farmacia pase a la Facultad de Ciencias Químicas] México, 24 de enero de 1919, fs. 11-12. 
y medicamentos; así como las habilidades necesarias para realizar análisis químicos y biológicos. Pensaban que esta nueva orientación hacia la química y sus aplicaciones les daba la posibilidad de ser algo más que el mero auxiliar del médico. Adicionalmente buscaron establecer una cátedra para los "prácticos» de ambos sexos, para convertirlos en eficaces auxiliares de los farmacéuticos, tal y como ellos lo habían sido de los médicos ${ }^{17}$.

Fue así como los farmacéuticos, ya instalados en 1919 dentro de la Facultad de Química y Farmacia, estuvieron en posibilidad de lograr sus aspiraciones de ponerse a la cabeza de los nacientes estudios y aplicaciones de la química en el país.

${ }^{17}$ Ahfm-unam. Escuela de Medicina y Alumnos, leg. 166, exp. 3. Proyecto para la fundación de la escuela Especial de Química y Farmacia. México, agosto 15 de 1916:, f. 13. 


\section{Colecçãa \\ 2 Ciências e Culturas Caimbra 2006}

